Check for updates

Cite this: RSC Adv., 2018, 8, 17944

Received 7th March 2018

Accepted 2nd May 2018

DOI: 10.1039/c8ra02017e

rsc.li/rsc-advances

\section{Preparation of boron nitride nanosheet-coated
carbon fibres and their enhanced antioxidant and \\ Preparation of boron nitride nanosheet-coated
carbon fibres and their enhanced antioxidant and microwave-absorbing properties $\uparrow$}

\author{
Zhichao Xu, Yongjun Chen, (D) Wei Li, Jianbao Li, Hui Yu, Longyang Liu, Gaolong Wu, \\ Tao Yang and Lijie Luo*
}

In this study, annealing carbon fibres with boron and $\mathrm{FeCl}_{3} \cdot 6 \mathrm{H}_{2} \mathrm{O}$ at elevated temperatures was demonstrated as a novel route to coat carbon fibres with boron nitride (BN) nanosheets. The effect of annealing temperature on the thickness and microstructure of $\mathrm{BN}$ coating was investigated. Results showed that BN coating hardly formed at $1000^{\circ} \mathrm{C}$, and uniform BN coating was achieved at $1100{ }^{\circ} \mathrm{C}$ and $1200{ }^{\circ} \mathrm{C}$. However, further increasing the temperature to $1250^{\circ} \mathrm{C}$ triggered the formation of discretely distributed $\mathrm{BN}$ particles on the surface of the BN coating in addition to the formation of a uniform BN coating. The BN coating and particles were constructed by numerous BN nanosheets with a bending and crumpling morphology. The thickness of the BN coating increased with increasing annealing temperature. The oxidation resistance of the carbon fibres dramatically enhanced after BN nanosheets were coated onto the carbon fibre surface. Moreover, given the low dielectric loss tangent of BN, the BN coating can improve the impedance matching of carbon fibres and enhance the microwave-absorbing property of carbon fibres significantly.

\section{Introduction}

Carbon materials are applied widely in the military, electronic, and infrastructure industries because of their low density, high specific modulus, high specific strength, excellent electrical conductivity, and chemical stability. ${ }^{1-3}$ As a form of carbon, carbon fibres have been used as wave absorbers and reinforced fillers in structural microwave-absorbing materials. ${ }^{4}$ However, carbon fibres are a strong radar reflector against electromagnetic waves in the high-frequency range because of their low electrical resistivity $\left(<10^{-3} \Omega \mathrm{m}\right) \cdot{ }^{4,5}$ Carbon fibres are also greatly susceptible to oxidation and can be oxidized at around $400{ }^{\circ} \mathrm{C} .{ }^{6}$ Thus, much effort has been exerted to modify carbon fibres with low-cost and light-weight coatings to improve their antioxidant property and microwave absorption property., ${ }^{5,7}$ By contrast, most studies mainly focused on the metal coating or metal oxide coating, ${ }^{9,10}$ which cannot effectively dissipate the electromagnetic energy when the application temperature exceeds the coatings' Curie temperatures. ${ }^{11}$

Boron nitride (BN) is a surface-modified material popular for its unique properties, such as low density, high electrical resistivity, good antioxidant property, low dielectric constant,

College of Materials and Chemical Engineering, State Key Laboratory of Marine Resource Utilization in South China Sea, Hainan University, Haikou 570228, China. E-mail:luolijie4567@163.com

$\dagger$ Electronic supplementary information (ESI) available. See DOI: 10.1039/c8ra02017e and excellent chemical inertness. ${ }^{12-14} \mathrm{BN}$ is also an isostructural analog to carbon with highly similar lattice parameters. These attributes render BN highly suitable in coating carbon fibres and enhancing the antioxidant and microwave-absorbing properties of such material., ${ }^{8,12,15-17}$ Currently, chemical vapor deposition (CVD) and the dip-coating method are mainly used to coat carbon fibres with BN. ${ }^{14,18-20}$ However, the CVD route usually requires hazardous and expensive precursor chemicals, whereas the dip-coating method is a complex process with a long preparation cycle. Therefore, a simple but effective route to coat carbon fibres with BN must be explored. In this study, given the solid-state reaction method developed in our group for the large-scale synthesis of BN micro-nanostructures, ${ }^{21} \mathrm{BN}$ nanosheets were coated onto carbon fibres by simple annealing with amorphous boron powder and $\mathrm{FeCl}_{3} \cdot 6 \mathrm{H}_{2} \mathrm{O}$ under an $\mathrm{NH}_{3}$ atmosphere at elevated temperatures. The thickness and microstructure of the $\mathrm{BN}$ coating can be controlled by varying the annealing temperature. The antioxidant and microwave absorption properties of the BN-nanosheet-coated carbon fibres were investigated in detail.

\section{Experimental}

\subsection{Treatment of carbon fibres}

PAN-based carbon fibres (T300, 3K, Toho Tenax, Inc.) were used in this study. A bundle of carbon fibres usually consists of $\sim 2000$ filaments with a typical filament diameter of about $5 \mu \mathrm{m}$. Prior to coating, the carbon fibres were heated at $800{ }^{\circ} \mathrm{C}$ in 
a nitrogen atmosphere to remove organic impurities. Then, the fibres were ultrasonically cleaned in acetone for $60 \mathrm{~min}$, followed by drying at $110^{\circ} \mathrm{C}$ for $1 \mathrm{~h}$. Herein, clean carbon fibres without sizing were obtained.

\subsection{The treatment of raw materials}

Amorphous boron powders (98\% purity, Dandong Chemical Co., Ltd., China) and $\mathrm{FeCl}_{3} \cdot 6 \mathrm{H}_{2} \mathrm{O}$ (analytical grade, Aladdin, Shanghai, China) were purchased and used without further purification. The molar ratio was $\mathrm{B}: \mathrm{FeCl}_{3} \cdot 6 \mathrm{H}_{2} \mathrm{O}=1: 0.05$. First, $\mathrm{FeCl}_{3} \cdot 6 \mathrm{H}_{2} \mathrm{O}$ was dissolved in absolute ethyl alcohol, and then $\mathrm{B}$ powders were added into the solution. The mixture was stirred in a water bath at $40{ }^{\circ} \mathrm{C}$ for $2 \mathrm{~h}$ to evaporate the solvent. Afterward, the obtained paste-like mixture was dried at $55^{\circ} \mathrm{C}$ to thoroughly remove the ethanol. Finally, a homogeneous mixture containing $\mathrm{B}$ and $\mathrm{Fe}$ was prepared that provides the boron source for the product.

\subsection{Preparation of BN coating on carbon fibres}

Fig. 1 illustrates the setup for coating BN onto carbon fibres. The carbon fibres used are $2 \mathrm{~mm}$ in length and $7 \mu \mathrm{m}$ in diameter in average. The mixture containing $\mathrm{B}$ and Fe prepared above was loaded into an alumina boat placed at the centre of a tube furnace. The clean carbon fibres were placed in the same boat next to the BN precursor along the direction of gas flow. Prior to heating up, high-purity $\mathrm{NH}_{3}$ flow was introduced to flush out the residual air in the chamber. Then, the furnace was heated to $1000-1250{ }^{\circ} \mathrm{C}$ at a rate of $10{ }^{\circ} \mathrm{C} \min ^{-1}$ under 50 $\mathrm{mL} \min ^{-1} \mathrm{NH}_{3}$ flow and maintained for $1 \mathrm{~h}$. Finally, the furnace was cooled naturally under the protection of $\mathrm{N}_{2}$ flow. The effect of reaction time (0.5-1.5 h) on the formation of BN coating was conducted and presented in the ESI. $\dagger$

\subsection{Characterization}

After the carbon fibres were removed from the furnace, they were characterized by Fourier transform infrared spectroscopy (FTIR; Bruker, TENSOR 27 spectrometer), X-ray photoelectron spectroscopy (XPS; ESCALAB 250Xi, Thermo Scientific) with Al $\mathrm{K} \alpha$ radiation, and scanning electron microscopy (SEM; JEM$1200 \mathrm{EX}$, equipped with EDS system). The antioxidant property of the BN-coated carbon fibres was measured in air with a DTA/ TGA instrument (STA 449C, NETZSCH). To test the microwaveabsorbing property of the samples, the carbon fibres with and without BN coating were cut into short fragments with length of about $2 \mathrm{~mm}$ (the average diameters are still about $7 \mu \mathrm{m}$ because of the thin thickness of BN coating), mixed with molten paraffin (in a mass ratio of $1: 4$ ), and then pressed into rings with inner

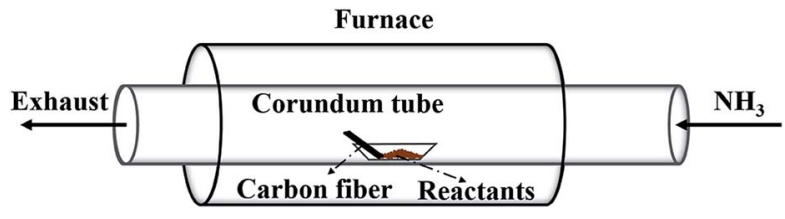

Fig. 1 Schematic illustration of the experimental apparatus. diameter $\times$ outer diameter $\times$ thickness $=3 \mathrm{~mm} \times 7 \mathrm{~mm} \times 2$ $\mathrm{mm}$. The electromagnetic parameters were measured by a coaxial line method in the frequency range of $2-18 \mathrm{GHz}$ using a network analyzer (AV3629). Four samples for each batch were measured to gain the average real part of permittivity $\left(\varepsilon^{\prime}\right)$ and the imaginary part of permittivity $\left(\varepsilon^{\prime \prime}\right)$ values.

\section{Results and discussion}

\subsection{Influence of annealing temperature}

Fig. 2 shows the SEM images of the carbon fibres coated with BN at annealing temperatures of $1000-1250{ }^{\circ} \mathrm{C}$. For comparison, the carbon fibres without BN coating were also characterized by SEM (Fig. 2a), showing the clean surfaces of the carbon fibres. Fig. $2 \mathrm{~b}$ indicates that no obvious BN coating can be found on the surfaces of the carbon fibres when the annealing temperature was $1000^{\circ} \mathrm{C}$. This result was achieved because very few BN species can be generated through the reaction of $\mathrm{B}$ and $\mathrm{FeCl}_{3}$ at

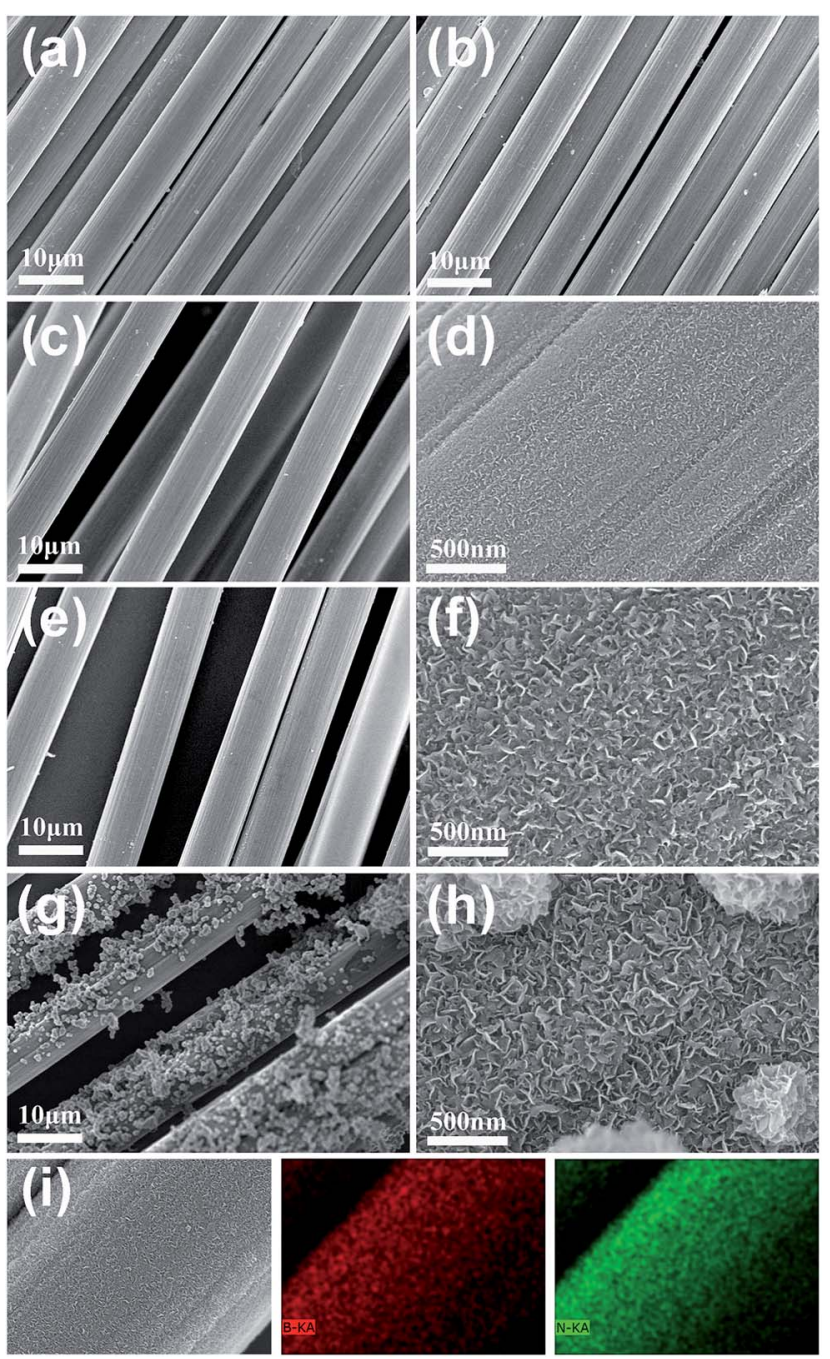

Fig. 2 Low and high magnification SEM images of the BN-coated carbon fibres prepared at different temperatures. (a) Without BN coating. (b) $1000^{\circ} \mathrm{C}$. (c) and (d) $1100^{\circ} \mathrm{C}$. (e) and (f) $1200^{\circ} \mathrm{C}$. (g) and (h) $1250^{\circ} \mathrm{C}$. (i) EDS elemental mapping of the $\mathrm{BN}$ coating prepared at $1200^{\circ} \mathrm{C}$ 
$1000{ }^{\circ} \mathrm{C}$. With the rise of annealing temperature (e.g., $1100{ }^{\circ} \mathrm{C}$ and $1200{ }^{\circ} \mathrm{C}$ ), an increasing number of $\mathrm{BN}$ species were generated and deposited onto the carbon fibres, which resulted in the thickening of BN coatings (Fig. 2c-f). Meanwhile, the magnified images (Fig. 2d and f) show that the coatings were constructed by numerous thin nanosheets. The nanosheets were mostly separated with a bending and crumpling morphology. Moreover, the sizes (thickness and width) of the nanosheets increased with increasing temperature. However, when the annealing temperature was further increased to $1250{ }^{\circ} \mathrm{C}$, many irregular particles formed on the coating surface (Fig. $2 \mathrm{~g}$ ). The magnified image (Fig. 2h) clearly reveals that these particles were also constructed by numerous nanosheets. Fig. 2i shows the elemental mapping of the $\mathrm{BN}$ coating prepared at $1200{ }^{\circ} \mathrm{C}$, implying the uniform distribution of $\mathrm{B}$ and $\mathrm{N}$ elements in the coating.

Thermodynamic calculation shows that the Gibbs free energies of the involved reactions are negative (eqn (1) and (2)), which indicates that the reactions can be occurred thermodynamically in the reaction temperature range $1000-1250{ }^{\circ} \mathrm{C}$. As a result, the thickness of the $\mathrm{BN}$ coating increased with the rise of temperature. However, the reactions may have proceeded very violently at $1250{ }^{\circ} \mathrm{C}$ and generated an excessive amount of $\mathrm{BN}$ species within a short period of time. Hence, surplus BN species deposited directly onto the surfaces of the already formed $\mathrm{BN}$ coating and caused the formation of $\mathrm{BN}$ nanosheets and even self-assembled BN particles by van der Waals forces. This process is highly similar to that of BN-nanosheetassembled microwires we reported previously. ${ }^{21}$

$$
\begin{aligned}
& \mathrm{FeCl}_{3}+\mathrm{B} \rightarrow \mathrm{BCl}_{3}(\mathrm{~g})+\mathrm{Fe}, \Delta G\left(1000-1250{ }^{\circ} \mathrm{C}\right) \\
&=-140.63 \text { to }-152.05 \mathrm{~kJ} \\
& \mathrm{BCl}_{3}(\mathrm{~g})+\mathrm{NH}_{3}(\mathrm{~g}) \rightarrow \mathrm{BN}+3 \mathrm{HCl}(\mathrm{g}), \Delta G\left(1000-1250^{\circ} \mathrm{C}\right) \\
&=-201.15 \text { to }-226.04 \mathrm{~kJ}
\end{aligned}
$$

\subsection{FTIR and XPS analyses}

Fig. 3 shows the FTIR spectra of carbon fibres with and without BN coating. The two absorption bands located at 1384 and $802 \mathrm{~cm}^{-1}$ were detected in the BN-coated carbon fibres prepared

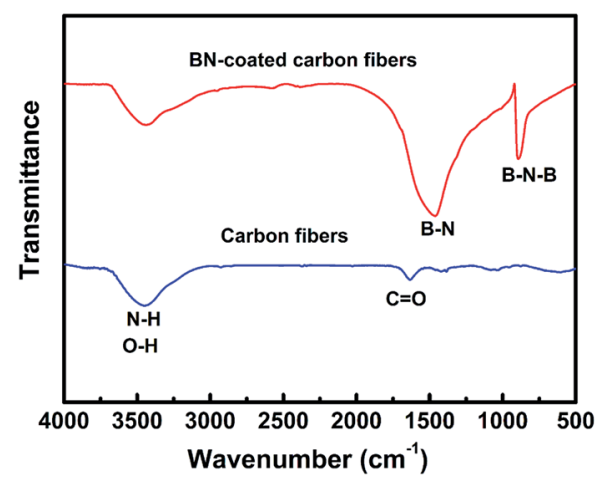

Fig. 3 FT-IR spectra of the clean carbon fibres and BN-coated carbon fibres fabricated at $1200{ }^{\circ} \mathrm{C}$. at $1200{ }^{\circ} \mathrm{C}$. These bands were attributed to the $\mathrm{B}-\mathrm{N}$ in-plane stretching vibrations and the $\mathrm{B}-\mathrm{N}-\mathrm{B}$ out-of-plane bending vibrations, respectively. ${ }^{22,23}$ Meanwhile, the band at $3407 \mathrm{~cm}^{-1}$ can be assigned to the stretching vibration of $\mathrm{O}-\mathrm{H}$ and $\mathrm{N}-\mathrm{H}$ bonds because of the absorbed water on the surfaces of $\mathrm{BN}$ coated carbon fibres. ${ }^{24}$

XPS is a powerful spectroscopic technique for characterizing surfaces with chemical bonding. Therefore, XPS was used to obtain additional information on the chemical composition of $\mathrm{BN}$ coating fabricated at $1200{ }^{\circ} \mathrm{C}$ (Fig. 4). All XPS data were corrected by using the binding energy (BE) of C-C at $284.6 \mathrm{eV}$.

Fig. 4a shows the XPS survey scan of BN coating and indicates the presence of $\mathrm{B}, \mathrm{N}, \mathrm{O}$, and $\mathrm{C}$ elements in the sample. The $\mathrm{C}$ signal can be ascribed to the carbon fibre or adventitious hydrocarbon from the XPS instrument itself. ${ }^{25}$ The narrow XPS spectra of B 1s and $\mathrm{N} 1 \mathrm{~s}$ are shown in Fig. $4 \mathrm{~b}$ and c, respectively. The $\mathrm{B}$ 1s peak at $190.4 \mathrm{eV}$ and the $\mathrm{N}$ 1s peak at $398.2 \mathrm{eV}$ were identified as B-N bonding and matched those reported for bulk h-BN. ${ }^{26}$ The B $1 \mathrm{~s}$ band was divided into two fine peaks located at 190.4 and $191.9 \mathrm{eV}$, respectively. The $190.4 \mathrm{eV}$ peak was assigned to the B-N bonding, ${ }^{27,28}$ whereas the peak at $191.9 \mathrm{eV}$ was assigned to the substitution of $\mathrm{N}$ by $\mathrm{O}$ in the $\mathrm{BN}$ lattice, i.e., the formation of $\mathrm{O}-\mathrm{B}$ or $\mathrm{O}-\mathrm{B}-\mathrm{N}$ bonds of $\mathrm{BN}_{x} \mathrm{O}_{y} .{ }^{29}$ The $\mathrm{N} 1$ s peak can also be divided into two fine peaks centred at 397.9 and $399.4 \mathrm{eV}$, respectively. The state of $\mathrm{N}$ at $397.9 \mathrm{eV}$ can be ascribed to the $\mathrm{N}-\mathrm{B}$ bonds, whereas the peak at $399.4 \mathrm{eV}$ was attributed to $\mathrm{N}-\mathrm{C}$ bonds, which agreed with the results reported in literature. ${ }^{30}$

\subsection{Oxidation resistance of BN-coated carbon fibres}

The oxidation resistance of the carbon fibres with and without $\mathrm{BN}$ coating was investigated by performing TGA test in air from room temperature to $900{ }^{\circ} \mathrm{C}$ (Fig. 5). Research found that the carbon fibres without BN coating began to be oxidized at about $500{ }^{\circ} \mathrm{C}$ and underwent rapid weight loss when the temperature
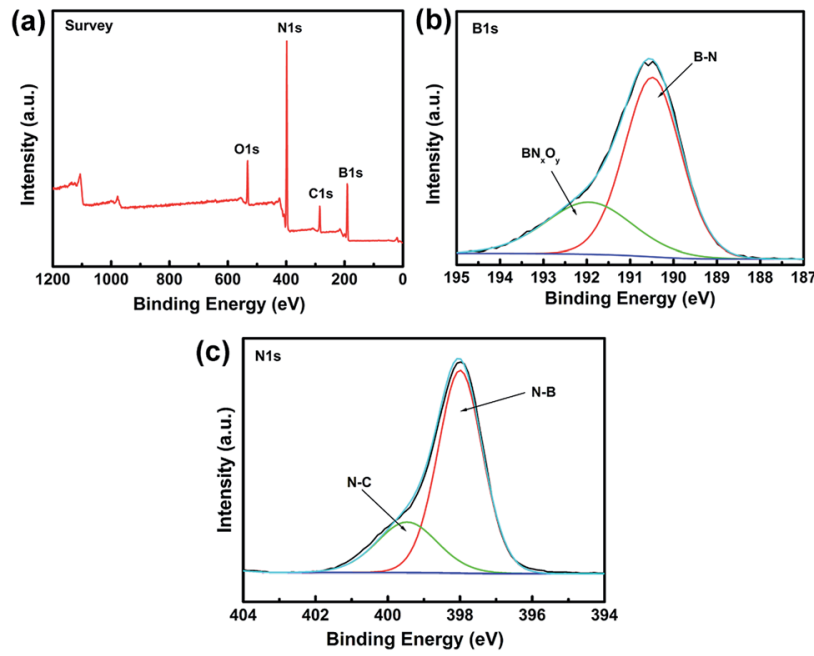

Fig. 4 XPS spectra of the BN-coated carbon fibres fabricated at $1200^{\circ} \mathrm{C}$. (a) Survey scan spectrum. (b) Fitted B 1s spectra. (c) Fitted N 1s spectra. 


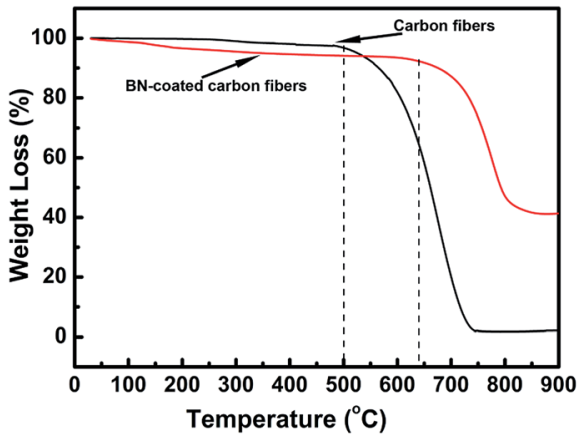

Fig. 5 TGA curves of clean carbon fibres and $\mathrm{BN}$-coated carbon fibres.

was increased. When the temperature was increased to $740{ }^{\circ} \mathrm{C}$, these carbon fibres were nearly completely oxidized with only about $1 \%$ residual weight. However, the starting oxidation temperature and end-oxidation temperature for the $\mathrm{BN}$-coated carbon fibres increased to about $640{ }^{\circ} \mathrm{C}$ and $850{ }^{\circ} \mathrm{C}$, respectively. Thus, the antioxidant property of the carbon fibres was improved efficiently by BN coating.

\subsection{Microwave-absorbing property}

According to Debye theory, the real part of permittivity $\left(\varepsilon^{\prime}\right)$ and the imaginary part of permittivity $\left(\varepsilon^{\prime \prime}\right)$ represent the storage ability and the dissipation ability of electromagnetic wave energy, respectively. Fig. $6 \mathrm{a}$ and b show the $\varepsilon^{\prime}$ and $\varepsilon^{\prime \prime}$ of the clean carbon fibres and $\mathrm{BN}$-coated carbon fibres measured at room temperature in the frequency range of 2-18 GHz. The $\varepsilon^{\prime}$ and $\varepsilon^{\prime \prime}$ values of the carbon fibres decreased obviously after BN coating, especially when the frequency was less than $8 \mathrm{GHz}$. This decrease may be attributed to the separation of dielectric relaxation and space charge polarization of carbon fibres after $\mathrm{BN}$ coating because $\mathrm{BN}$ possesses a high electrical resistivity. ${ }^{31}$
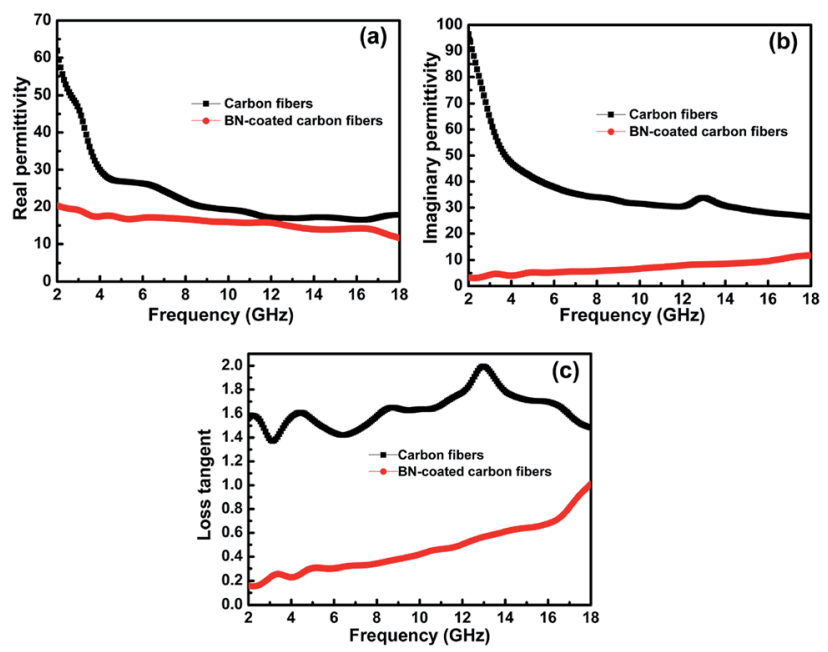

Fig. 6 Frequency dependence of (a) the real parts and (b) the imaginary parts of permittivity, and the corresponding dielectric loss (c) of the carbon fibres with and without $\mathrm{BN}$ coating.
In addition, the extremely low dielectric constant and low dielectric loss of $\mathrm{BN}$ can also help decrease the complex permittivity of carbon fibres. ${ }^{1}$

Herein, the microwave attenuation of the samples was mainly attributed to dielectric loss rather than magnetic loss. ${ }^{32}$ Fig. $6 \mathrm{c}$ shows that the dielectric loss tangent $(\tan \delta)$ of the $\mathrm{BN}-$ coated carbon fibres was smaller than that of the clean carbon fibres in the measured frequency range. To obtain good impedance matching, the values of $\tan \delta$ should be approximately equal to the magnetic tangent loss. ${ }^{33}$ Carbon fibres reflect microwaves highly because their dielectric loss tangent is obviously higher than their magnetic loss tangent. Hence, the BN coating with a low dielectric loss tangent can narrow the gap between the dielectric and magnetic loss tangents of carbon fibres.

To further describe the microwave-absorbing property of the samples, the reflection loss (RL) of the carbon fibres with and without BN coating was calculated in accordance with the following equations by using the single-layer model: ${ }^{33,34}$

$$
\begin{gathered}
\mathrm{RL}(\mathrm{dB})=20 \log _{10}\left|\frac{Z_{\text {in }}-1}{Z_{\text {in }}+1}\right| \\
Z_{\text {in }}=\sqrt{\frac{\mu_{\mathrm{r}}}{\varepsilon_{\mathrm{r}}}} \tan h\left[j\left(\frac{2 \pi f d}{c}\right) \sqrt{\mu_{\mathrm{r}} \varepsilon_{\mathrm{r}}}\right]
\end{gathered}
$$

where $Z_{\text {in }}$ is the normalized input impedance relative to the impedance in free space, $f$ is the microwave frequency, $c$ is the light velocity, $d$ is the thickness of the absorber, and $\varepsilon_{\mathrm{r}}$ and $\mu_{\mathrm{r}}$ are the complex permittivity and complex permeability of materials, respectively. Therefore, the $R$ values versus frequency can be evaluated at a specified thickness. Fig. 7 shows the calculated RL of the samples (thickness 1-4.5 mm) with and without $\mathrm{BN}$ coating in the frequency range of $2-18 \mathrm{GHz}$. As shown in Fig. 7a, the RL values of the clean carbon fibres were larger than $-4 \mathrm{~dB}$ in the frequency range of $2-18 \mathrm{GHz}$. This poor microwave absorption performance was mainly caused by the poor impedance matching and most microwaves were reflected by the front of the sample surface. ${ }^{35}$ Fig. $7 \mathrm{~b}$ illustrates that the BN coating improves the microwave-absorbing property of the carbon fibres significantly, and the RL values are listed in Table 1. Meanwhile, the dependence of RL values on sample thickness can be concluded.

The lowest $\mathrm{RL}$ can reach $-26.8 \mathrm{~dB}$ at $3.5 \mathrm{GHz}$ with a sample thickness of $4.0 \mathrm{~mm}$. The widest frequency range where $R$ is lower than $-10 \mathrm{~dB}$ was 8.6-10.4 GHz when the sample thickness
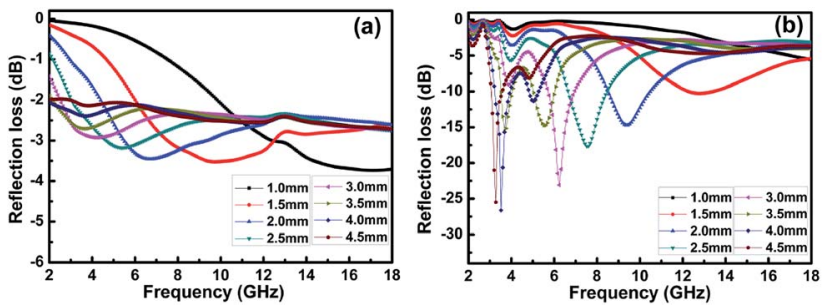

Fig. 7 Frequency dependence of RL for (a) clean carbon fibres and (b) $\mathrm{BN}$-coated carbon fibres with different thickness. 
Table 1 The electromagnetic microwave absorption properties of BN/ carbon fibre based absorbers with different thickness

\begin{tabular}{llc}
\hline $\begin{array}{l}\text { Thickness } \\
(\mathrm{mm})\end{array}$ & $\begin{array}{l}\text { Min RL value } \\
(\mathrm{dB})\end{array}$ & $\begin{array}{l}\text { Frequency } \\
(\mathrm{GHz})\end{array}$ \\
\hline 1.0 & -5.60 & 18.00 \\
1.5 & -10.40 & 12.73 \\
2.0 & -14.85 & 9.32 \\
2.5 & -17.72 & 7.56 \\
3.0 & -22.97 & 6.17 \\
3.5 & -15.57 & 3.68 \\
4.0 & -26.79 & 3.45 \\
4.5 & -25.52 & 3.24
\end{tabular}

was $2.0 \mathrm{~mm}$. In addition, $\mathrm{RL}$ values less than $-10 \mathrm{~dB}$ can be gained in the 2.9-13.4 GHz range with sample thicknesses of 1.5-4.5 $\mathrm{mm}$. This result means that the microwave absorption performance of the carbon fibres in different frequency bands can be adjusted by varying the sample thickness. A material with an RL value less than $-20 \mathrm{~dB}$ is an excellent absorber because this value corresponds to a microwave absorption of 99.99\%. ${ }^{34}$ Therefore, we conclude that the microwave-absorbing property of carbon fibres can be significantly enhanced by $\mathrm{BN}$ coating through the reduction of microwave reflection.

\section{Conclusions}

BN coatings have been successfully deposited on the surface of carbon fibres by annealing amorphous boron powder with $\mathrm{FeCl}_{3} \cdot 6 \mathrm{H}_{2} \mathrm{O}$ under flowing ammonia atmosphere at 1100$1250{ }^{\circ} \mathrm{C}$. The thickness of coating increases with the rise of annealing temperature and uniform coatings can be obtained at 1100-1200 ${ }^{\circ} \mathrm{C}$. The coatings consist of numerous BN nanosheet which are mostly separated with a bending and crumpling morphology. Irregular BN particles are formed and distributed discretely on the $\mathrm{BN}$ coating when the temperature increases to $1250{ }^{\circ} \mathrm{C}$, which are also constructed of $\mathrm{BN}$ nanosheets. The antioxidation property of carbon fibres is improved significantly by $\mathrm{BN}$ coating, with start oxidization temperatures increasing from 500 to $640{ }^{\circ} \mathrm{C}$. In addition, the complex permittivity of BNcoated carbon fibres decreases greatly due to the extremely low dielectric constant, low dielectric loss and high electrical resistivity of $\mathrm{BN}$ coatings. The carbon fibres with $\mathrm{BN}$ coating show a strong absorption peak at $3.5 \mathrm{GHz}$, where the lowest reflectivity can reach $-26.8 \mathrm{~dB}$. Moreover, the reflection loss less than $-10 \mathrm{~dB}$ is over the range of $2.9-13.4 \mathrm{GHz}$, indicating an excellent microwave absorbing property of the BN-coated carbon fibres. Therefore, it is an effective modification approach to enhance the oxidation resistance and microwave absorbing properties of carbon fibres.

\section{Conflicts of interest}

There are no conflicts to declare.

\section{Acknowledgements}

The work is supported by the National High Technology Research and Development Program of China (863 Program, No. 2015AA034103), National Natural Science Foundation of China (No. 51702072 and 51362008).

\section{Notes and references}

1 M. S. Cao, W. L. Song, Z. L. Hou, B. Wen and J. Yuan, Carbon, 2010, 48, 788.

2 M. Zhang, S. L. Fang, A. A. Zakhidov, S. B. Lee, A. E. Aliev, C. D. Williams, K. R. Atkinson and R. H. Baughman, Science, 2005, 309, 1215.

3 Y. Zhang, Z. Wang, B. l. Zhang, C. J. Zhou, G. L. Zhao, J. C. Jiang and S. M. Guo, J. Mater. Chem. C, 2015, 3, 9684.

4 B. Cheng, J. Wang, F. Zhang and S. Qi, Polym. Bull., 2017, 28, 1.

5 O. Khani, M. Z. Shoushtari, M. Jazirehpour and M. H. Shams, Ceram. Int., 2016, 42, 14548.

6 W. Zhou, X. Peng and Y. Li, Appl. Surf. Sci., 2012, 258, 8455.

7 S. E. Lee, W. J. Lee, K. S. Oh and C. G. Kim, Carbon, 2016, 107, 564.

8 B. Bonnetot, F. Guilhon, J. C. Viala and H. Mongeot, Chem. Mater., 1995, 7, 299.

9 H. Salimkhani, A. M. Dizaji, E. Hashemi, P. Palmeh, G. Sabeghi and S. Salimkhani, Ceram. Int., 2016, 42, 12709.

10 J. Zeng, H. Fan, Y. Wang, S. Zhang, J. Xue and C. Zhang, J. Alloys Compd., 2012, 524, 59.

11 Y. Wang, W. Zhang, C. Luo, X. Wu and G. Yan, Ceram. Int., 2016, 42, 12496.

12 D. Golberg, Y. Bando, Y. Huang, T. Terao, M. Mitome, C. C. Tang and C. Y. Zhi, ACS Nano, 2010, 4, 2979.

13 D. S. Williams, J. Appl. Phys., 1985, 57, 2340.

14 D. F. Lii, J. L. Huang, L. J. Tsui and S. M. Lee, Surf. Coat. Technol., 2002, 150, 269.

15 D. P. Kim and J. Economy, Chem. Mater., 1993, 5, 1216.

16 M. Nose, T. Kawabata, T. Watanuki, S. Ueda, K. Matsuda and S. lkeno, Surf. Coat. Technol., 2011, 205, 533.

17 Y. Yu, R. Y. Luo, Q. Xiang, Y. Zhang and T. Y. Wang, Surf. Coat. Technol., 2015, 277, 7.

18 C. Lorrette, P. Weisbecker, S. Jacques, R. Pailler and J. M. Goyhénèche, J. Eur. Ceram. Soc., 2007, 27, 2737.

19 J. S. Li, C. R. Zhang and B. Li, Appl. Surf. Sci., 2011, 257, 7752. 20 X. Li, Q. F. Li and G. X. Chen, Mater. Lett., 2014, 134, 38.

21 A. Pan, Y. J. Chen and J. B. Li, Crystengcomm, 2015, 17, 1098. 22 T. Zhang, G. Wen, L. Xia, X. X. Huang, B. Zhong, X. D. Zhang and H. W. Bai, Scr. Mater., 2010, 63, 415.

23 F. Yuan, W. C. Jiao, F. Yang, W. B. Liu, J. Y. Liu, Z. H. Xua and R. G. Wang, J. Mater. Chem. C, 2017, 5, 6359.

24 J. H. Wu, L. C. Wang, B. L. Lv and J. G. Chen, ACS Appl. Mater. Interfaces, 2017, 9, 14319.

25 D. M. Chen, D. Yang, Q. Wang and Z. Y. Jiang, Ind. Eng. Chem. Res., 2006, 45, 4110.

26 Y. C. Su, Z. Y. Juang, K. F. Chen, B. M. Cheng, F. R. Chen, K. C. Leou and C. H. Tsai, J. Phys. Chem. C, 2009, 113, 14681. 
27 C. Guimon, D. Gonbeau, G. Pfister-Guillouzo, O. Dugne, A. Guette, R. Naslain and M. Lahaye, Surf. Interface Anal, 1990, 16, 440.

28 L. X. Hou, Z. G. Chen, X. H. Liu, Y. J. Gao and G. Jia, Appl. Surf. Sci., 2012, 258, 3800.

29 M. Hubáček, T. Sato and T. Ishii, J. Solid State Chem., 1994, 109, 384.

30 W. Zhou, P. Xiao, Y. Li and L. Zhou, Ceram. Int., 2013, 39, 6569.

31 S. S. Kim, S. T Kim, J. M. Ahn and K. H. Kim, J. Magn. Magn. Mater., 2004, 271, 39.
32 J. Zeng, P. Tao, S. Wang and J. Xu, Appl. Surf. Sci., 2009, 255, 4916.

33 B. Zhong, W. Liu, Y. Yu, L. Xia, J. Zhang and Z. Chai, Appl. Surf. Sci., 2017, 420, 858.

34 L. H. Tian, X. D. Yan, J. L. Xu, P. Wallenmeyer, J. Murowchick, L. Liu and X. B. Chen, J. Mater. Chem. A, 2015, 3, 12550.

35 J. N. Ma, X. M. Zhang, W. Liu and G. B. Ji, J. Mater. Chem. C, 2016, 4, 11419. 